\title{
Aproximación a las implicancias gnoseológicas del pluralismo nietzscheano según Deleuze
}

Gabriel M. Torres

(UNNE- S.G.C.YT.)

lubary_@hotmail.com

Recibido 1/06/2016

Aprobado 20/08/2016

\section{Introducción}

A lo largo del siglo XX se desarrollaron diversas críticas desde el campo de la filosofía a la idea establecida en la modernidad respecto del conocimiento científico. La mayoría de las veces se trataron de intentos de reformular el tradicional concepto de racionalidad, buscando echar luz sobre los diferentes influjos que afectan la pretendida autonomía del intelecto (sea otra idea de historia, el lenguaje, los instintos, u otros factores). ${ }^{1}$ Aunque en una primera impresión la filosofía de Gilles Deleuze puede sugerir una distancia respecto de inquietudes gnoseológicas o epistemológicas, como se pretenderá demostrar a continuación la misma constituye un significativo exponente de esta tendencia crítica.

En este sentido, el presente escrito tiene como objetivo central presentar una esquemática aproximación a lo que puede concebirse como una crítica y reformulación

1 De entre las diversas fuentes más representativas de tales líneas, se pueden mencionar las siguientes: HUSSERL, Edmund, La crisis de las ciencias europeas y la fenomenología transcendental. Trad. Jacobo Muñoz y Salvador Más. Barcelona, Critica, 1991, pp. 5-11 y 50-54; HEIDEGGER, Martin, El Ser y el tiempo. Trad José Gaos. México, Fondo de Cultura Económica, 1971, pp. 65-75 y 247-252; ALTHUSSER, Louis, BALIBAR, Etienne, Para leer El Capital. Trad. Marta Harnecker. Siglo XXI, Buenos Aires, 2004 (Prefacio); y HABERMAS, Jurgen, Teoría de la acción comunicativa I. Racionalidad de la acción y racionalización social. Trad. Manuel Jiménez Redondo. Madrid, Taurus, 2003, pp. 357 y ss. 
del problema del conocimiento tal como fue expuesto por Deleuze a través de su particular exégesis del pensamiento nietzscheano en el libro Nietzsche y la filosofía. ${ }^{2}$

Para cumplir este objetivo, el desarrollo se encuentra dividido en cuatro instancias. En la primera se procederá a exponer sintéticamente la ontología que Deleuze localiza en la confluencia entre los conceptos voluntad de poder y eterno retorno, especialmente en función de aquello elementos especulativos que resultan significativos para el tratamiento del problema de la verdad, tales como la jerarquía de la diferencia y la actividad. En la segunda se pretenderá focalizar la atención en la crítica al concepto de verdad desde el enfoque genealógico que Deleuze recupera. Si lo anterior apunta al esclarecimiento del rol del pensamiento en el marco de la voluntad negativa, el objetivo del siguiente apartado es precisar las particularidades del margen positivo que le cabe al pensar ahora en el contexto de una afirmación de la vida. Finalmente, el último tramo aspira a presentar un balance de las implicancias gnoseológicas globales de la lectura deleuziana de Nietzsche, en atención a las relaciones entre conocimiento, ciencia y la concepción pluralista de lo real.

Palabras clave: Nietzsche-Deleuz-Gnoseología-Pluralismo

\section{Abstract}

The main objective of this paper is to present a schematic approach to what can be conceived as a critique and reformulation of the problem of knowledge as it was exposed by Deleuze through his particular exegesis of Nietzschean thought.

To achieve this goal, the development is divided into four instances. In the first, the ontology that Deleuze locates at the confluence between the concepts will of power and eternal return will be synthetically presented, especially in terms of speculative elements that are significant for the treatment of the problem of truth, such as the hierarchy of the difference and the activity. In the second, attention will be focused on criticizing the concept of truth from the genealogical approach that Deleuze recovers. If the above points to the clarification of the role of thought in the context of negative will, the purpose of the next section is to specify the particularities of the 
positive margin that fits you when thinking now in the context of an affirmation of life. Finally, the last section aims to present a balance of the global epistemological implications of the Deleuzian reading of Nietzsche, in attention to the relations between knowledge, science and the pluralist conception of the real.

Keywords: Nietzsche-Deleuz-Gnoseology-Pluralism

\section{La ontología nietzscheana como pluralismo intensivo}

Es posible suponer que la problematización del concepto de conocimiento presente en Nietzsche y la filosofía se despliega en el marco del cruce entre dos grandes cuestiones: por un lado, la elaboración de una ontología articulada en torno a la identificación entre la diferencia y el ser, y asimismo entre la diferencia y la repetición; por otro lado, la elucidación de una ética que no tome al sufrimiento como principio. Ambas cuestiones integran lo que puede tomarse como el hilo conductor de tal obra: la pormenorizada reconstrucción que Deleuze lleva a cabo de la crítica nietzscheana dirigida al nihilismo.

Deleuze se remite al concepto voluntad de poder y a la doctrina del eterno retorno presentes en las últimas obras de Nietzsche para precisar una concepción pluralista de lo real que pueda cumplir el siguiente principio: afirmar la diferencia sin subordinarla a la identidad.

En lo relativo a la noción voluntad de poder, Deleuze se vale de lo que podría llamarse la "filosofía de la naturaleza" allí implicada para establecer, en primer lugar, que todo cuerpo puede ser concebido como una unidad sintética de fuerzas que es en sí misma heterogénea. ${ }^{3}$ El carácter pluralista de este idea se encontraba en el énfasis puesto por Nietzsche en concebir la relación entre fuerzas (o, lo que es lo mismo, a la voluntad de poder) como una diferencia radical, no sólo cuantitativa sino cualitativa. ${ }^{4}$

$3 \quad$ "El concepto de fuerza es (...) en Nietzsche, el de una fuerza relacionada con otra fuerza: bajo este aspecto, la fuerza se llama una voluntad. La voluntad (voluntad de poder) es el elemento diferencial de la fuerza." Ibíd, p. 15

Ver ibíd., pp. 64 y 66. 
Concretamente, se trata de una asimetría imposible de nivelar sino es a costa de desvirtuar lo propio de las fuerzas. ${ }^{5}$

Según Deleuze, uno de los mayores aportes del nietzscheanismo era la asociación establecida entre este pluralismo y la radicalización del carácter inmanente de los principios determinantes de lo real respecto de sus objetos. Esto se debía a que, en la medida en que para la filosofía de la voluntad nietzscheana toda determinación positiva, toda realidad o consistencia de un cuerpo dado, remite a dicha relación entre sus componentes (a la relación entre las fuerzas), la razón de ser de cualquier fenómeno debe ser pensada como una causalidad esencialmente interna a sus efectos. Es decir, como un principio determinante que no emana de ninguna realidad trascendente a sus determinaciones, sino de cada específica forma de vida:

Nietzsche reprocha a los principios el ser siempre demasiado generales en relación a lo que condicionan (...) Si, al contrario, la voluntad de poder es un buen principio, si reconcilia al empirismo con los principios, si constituye un empirismo superior, es porque es un principio esencialmente plástico, que no es más amplio que lo que condiciona, que se metamorfosea con lo condicionado...6

Si la voluntad es el principio genético de las fuerzas, operando como complemento interno, puede decirse por lo tanto que hay una dinámica autoproductiva en el ser de todo lo viviente. Aquí resulta importante destacar que, según Deleuze, así como en el naturalismo pluralista nietzscheano se descarta la separación entre principios determinantes y las realidades así determinadas por tratarse de una abstracción metafísica, también constituye un problema identificar sin más tales términos (en este caso, la voluntad con la fuerza) ya que supondría otra distorsión de la condición esencialmente múltiple de toda vida. Más precisamente, confundir la fuerza con la relación entre las fuerzas implica no dar cuenta de la disposición en la

\footnotetext{
5 "Soñar con dos fuerzas iguales, incluso si se les concede una oposición de sentido es un sueño aproximativo y grosero..." ibíd, p. 65

lbíd., p. 74
} 
composición de las singularidades, el gobierno o la jerarquía correspondiente a esa unidad heterogénea. ${ }^{7}$

En lo relativo a la doctrina nietzscheana del eterno retorno, Deleuze proyectó a través de ella una especulación cosmológica que concibe al tiempo desde una disparidad elemental, específicamente como la repetición de la diferencia en la reproducción del pasar de instantes siempre desiguales entre sí. $^{8}$ La clave de esta concepción del tiempo era la yuxtaposición mantenida entre ser y devenir, que elevaba el cambio a esencia última de todo lo que es. De este modo, las ideas sean de un origen fundamental del devenir o de un término final del mismo resultaban descartadas (asumidas como residuos teológicos dentro de lo que debería ser un radical pensamiento sobre el tiempo), conduciendo así al pensar del "puro devenir". ${ }^{9} \mathrm{El}$ tiempo puede ser pensado entonces como el pasar o la repetición de instantes donde lo permanente o idéntico no es ninguna sustancia sino la misma repetición, la diferencia. Como resultado, si se acepta que no hay origen ni fin fuera de la vida misma, un atributo básico de la realidad -junto con la diferencia y el devenir- resulta ser el azar. Deleuze considera incluso que el reconocimiento del azar como verdad de la existencia era la síntesis del sentimiento trágico al que Nietzsche volcó tanta atención en su vida. Por el contrario, este sentimiento resulta incomprendido cuando se lo asocia con el sufrimiento experimentado como dolor ante la infinita diferencia del ser. ${ }^{10}$

En consecuencia, en tanto se considere todo cuerpo en su dimensión eminentemente móvil, en su conducta o trayectoria, este acontecer se tratará siempre, en su profundidad, de una serie de repeticiones sin una sustancia (sin un sujeto de repetición) detrás o futuro; se tratará por el contrario de un flujo de puras repeticiones que transgreden las regularidades, es decir las repeticiones que proyectan una identidad o semejanza. Por lo tanto, desde esta perspectiva se supone que los fenómenos no tienen identidades subyacentes ni tampoco constantes dentro de su

\footnotetext{
7 "el concepto de fuerza es victorioso por naturaleza, porque la relación de la fuerza con la fuerza, tal como está entendida en el concepto, es la de la dominación: de dos fuerzas en relación, una es dominante; la otra, dominada". Ibíd, p. 75

$8 \quad$ "Jamás el instante que pasa podría pasar, si no fuera ya pasado al mismo tiempo que presente, todavía futuro al mismo tiempo que presente." Ibíd., p. 71-72

$9 \quad$ Ver ibíd., p. 71

$10 \quad$ Ver ibíd., pp. $28-30$ y 55.
} 
movimiento, sino que corresponden a complejos dotados de una magnitud singular, una diferencia con un respectivo grado. ${ }^{11}$

La última nota que podría añadirse a esta caracterización del vitalismo pluralista nietzscheano consiste en que, según Deleuze, la materia de la determinación de toda fuerza es la temporalización -o el fluir- de la acción, el modo en que experimenta el pasar del tiempo desde el ejercicio de su propia potencia. En función de esto, la distinción básica de las fuerzas puede ser planteada según el polo activas/pasivas. Mientras la cualidad activa designa la tendencia a afirmar la variación, cuyo máximo grado es la transformación, la cualidad reactiva es propia de fuerzas que niegan el cambio, afirmando la conservación y la adaptación. ${ }^{12} \mathrm{Y}$ más profundamente, la cualidad de las voluntades se especifica a través de la distinción entre afirmativas, nobles, o altas y negativas, viles, o bajas, como afinidad con lo activo en el primer caso o complicidad con la reactividad para el segundo. ${ }^{13}$

La concepción de lo real así planteada, que tiene como eje a la diferencia o, más precisamente, a la diferenciación en tanto inmediata repetición de la diferencia, conduce en resumidas cuentas a una "física de cantidades intensivas". ${ }^{14}$ Esta ontología intensiva se encuentra signada por la disparidad que se manifiesta tanto como diferir en el tiempo y como asimetría o multiplicidad en el espacio, y entiende todo acontecer como fundado en definitiva en la necesidad del azar.

\section{El rol del conocimiento en la articulación negativa entre pensamiento y vida}

\footnotetext{
11 De este modo, en la obra posterior Diferencia y repetición Deleuze dirá que la naturaleza misma debe ser vista como una gran serie de repeticiones donde las supuestas leyes no son "la última palabra" sino la repetición de la diferencia como expresión de una voluntad artista que transgrede toda regularidad: "Si la repetición puede ser hallada, aún en la naturaleza, lo es en nombre de una potencia que se afirma contra la ley, que trabaja por debajo de las leyes, que puede ser superior a ellas. Si la repetición existe, expresa al mismo tiempo una singularidad contra lo general, una universalidad contra la particularidad." DELEUZE, Gilles, Diferencia y repetición. Trad. María Silvia Delpy y Hugo Beccacece. Buenos Aires, Amorrortu, 2002, p. 23

12 Ver DELEUZE, Gilles, Nietzsche y la filosofía. Op. Cit, p. 64 y p. 61 respectivamente. 13 Ibíd. p. 79

14 "En verdad, Nietzsche se interesaba por la física como ciencia de las cantidades intensivas, y contemplaba, más allá de ella, la voluntad de poder como principio 'intensivo', como principio de intensidad pura." DELEUZE, Gilles, "Conclusiones sobre la voluntad de poder y el eterno retorno", en La isla desierta y otros textos. Textos y entrevistas (1953-1974). Trad. José Luis Pardo, Valencia, Pre-textos, 2005, p. 161
} 
La distinción entre el nivel de las fuerzas y el nivel de la voluntad es decisiva de cara a la faceta práctica de la filosofía nietzscheana. En virtud de los supuestos e implicancias derivados de tal precisión resulta viable una crítica como evaluación de las formas de vida que logre mantener distancia tanto de las posturas idealistas (que remiten la existencia a valores eternos e incuestionables) como también del utilitarismo (doctrina que retrotrae los valores a la vida pero al precio de sustraerles la pluralidad y su jerarquía). ${ }^{15}$ Para allanar el camino a una afirmación correlativa a esta doble crítica, resulta necesario retener el aporte genealógico del concepto nietzscheano de voluntad: considerar que toda forma de vida cuenta con condiciones inherentes, los modos de vida, voluntades o valoraciones, las cuales no son objetividades absolutas sino más bien circunstancias sujetas a su vez a la variación y al cambio. Más que contemplar que hay valores condicionando a la acción, se trata de pensar en las valoraciones o modos de existencia como los principios genéticos de los que derivan los actos o creencias. ${ }^{16}$ Toda interpretación remite por lo tanto a una voluntad. ${ }^{17}$

Así, si la existencia llegó a ser interpretada como sufrimiento, si el sentido de la vida se identificó con una contradicción, fue desde una específica valoración: desde la jerarquía de la negación sobre la afirmación y su concomitante desactivación de las fuerzas activas, reduciendo la intrínseca pluralidad del ser a la precariedad de una oposición. El concepto que reúne la dimensión especulativa con la práctica desde esta cualificación es el nihilismo, el espíritu de venganza contra la vida. Como Deleuze destaca, no se trata tanto de una manera más entre otras de concebir la realidad o incluso el pensamiento sino la raíz desde la cual brotaron la metafísica, la teoría del conocimiento, la moral. ${ }^{18}$ Es así que en la reconstrucción que realiza Deleuze de la obra

\footnotetext{
15 Ver DELEUZE, Gilles, Nietzsche y la filosofía. Op cit. pp. 8-9

16 "Las valoraciones no son valores sino modos de ser, modos de existencia de los que juzgan y valoran, sirviendo precisamente de principios a los valores en relación a los cuales juzgan" Ibíd., p. 8

17 "La voluntad de poder como elemento genealógico es aquello de lo que derivan la significación del sentido y el valor del valor." ibíd., p. 121

18 "...el instinto de venganza es la fuerza que constituye la esencia de lo que nosotros llamamos psicología, historia, metafísica y moral. El espíritu de venganza es el elemento genealógico de nuestro pensamiento." ibíd, p. 54
} 
nietzscheana el tema del conocimiento adquiere relevancia en la medida en que constituye un punto decisivo dentro de la crítica dirigida a la valoración negativa paradigmática de la cultura occidental.

En la sección "La crítica" de Nietzsche y la filosofía Deleuze sostiene que para Nietzsche una crítica total debe partir de principios que den cuenta de la génesis interna de sus objetos, sin contentarse con determinar condicionamientos todavía exteriores de supuestos hechos, como ocurría todavía en la filosofía trascendental. En consecuencia, una perspectiva plástica y genética (afín a un "empirismo superior") exige una actividad eminentemente productiva: la creación de tipos, como respuesta a la pregunta por el sentido y el valor ya no de simples hechos, sino de síntomas de una voluntad. En esto consiste precisamente el método de la dramatización propuesto por Nietzsche. ${ }^{19}$

Cuando dicha dramatización se practica sobre el conocimiento, la pregunta por el tipo correspondiente a la voluntad de verdad indica, en el marco del nihilismo, la existencia de un encadenamiento secreto entre el ascetismo, la moral y el conocimiento. Esto se debe a que la indagación en la posición especulativa que se expresa como el "querer la verdad en sí misma" conduce al develamiento de una oposición moral: contraponer la vida al conocimiento desde el anhelo de un mundo mejor. A su vez, el análisis de esta contraposición desemboca en la revelación de la contradicción ascética: la vida contra la vida, como puente al mundo superior. Lo que resulta un invariante en este desarrollo de valores superiores, en el encadenamiento entre la verdad, el bien y lo divino, es en definitiva el "ideal ascético". ${ }^{20}$ Este ideal es tanto el tercer momento de la serie como el motor oculto de las dos primeras fases; es decir, es quien anima todo desde el principio: "Esta voluntad de negar la vida define el 'valor' de los valores superiores". ${ }^{21}$ Dicha valoración se define, en síntesis, como el deseo de la vida limitada, empequeñecida.

19 "De acuerdo con la terminología de Nietzsche, hay que decir: cualquier fenómeno remite a un tipo que constituye su sentido y su valor, pero también a la voluntad de poder como al elemento del que derivan la significación de su sentido y el valor de su valor." Ibíd., p. 121

$20 \quad$ "La voluntad de la nada y las fuerzas reactivas, estos son los dos elementos constituyentes del ideal ascético". Ibíd., p. 137

$21 \quad$ Cfr. Ibíd., p. 137 
Según Deleuze la ruptura con el desarrollo de este ideal se encuentra en el regreso al punto de partida, la posición especulativa o la verdad en sí, para tomarla como objeto de una radical crítica. La única forma de desenmascarar al ideal ascético es entonces planteando una crítica de la voluntad de verdad..$^{22}$ Esta específica instancia, la crítica de la verdad en sí, constituye el punto decisivo, la ruptura con el dominio del nihilismo, porque al plantear la pregunta por el sentido y el valor de la voluntad de verdad se destruye la condición que sostiene la creencia en la verdad en sí. Se rompe la supuesta unión esencial entre pensamiento y verdad, exponiendo las condiciones reales, concretas, del dogma que oficia de último sostén de la voluntad negativa.

La disolución de la abstracción propia del concepto de "verdad en sí" acontece entonces en virtud de una indagación especialmente atenta a la complejidad de los fenómenos; esto es, atenta a la necesidad de dar cuenta de los condicionamientos internos de aquello que es un síntoma: sólo cuando se distingue la reactividad de la negación, y la alianza entre ambos en términos de medios y fines, es factible una genuina liberación de esa misma alianza. ${ }^{23}$ Podría decir que entonces resulta posible pensar al nihilismo en su radicalidad. De este modo puede comprenderse uno de los motivos que hacen que la crítica nietzscheana como transmutación resulte una consistente expulsión del nihilismo: "únicamente al cambiar el elemento de los valores se destruyen todos los que dependen del viejo elemento".24

Si bien en este proceso descendente hay una búsqueda de conocimiento, lo que se busca es un concepto de verdad que presuponga una voluntad completamente distinta, radicalmente diferente a la voluntad de lo verdadero. Deleuze sostiene que en la denuncia del ocultamiento del ideal ascético en la voluntad de verdad "también nosotros somos los 'verídicos' o los 'buscadores de conocimiento'" ${ }^{25}$, pero advierte de

22 “...el planteamiento de la voluntad de verdad (su interpretación y evaluación) debe impedir al ideal ascético hacerse reemplazar por otros ideales que le prolongarían bajo otras formas" Ibíd., p. 140

23 Para Deleuze la tendencia a no dar cuenta de esta complejidad tiene su caso paradigmático en el pensamiento dialéctico: "La dialéctica ignora el elemento real del que proceden las fuerzas, sus cualidades y sus relaciones; de este elemento conoce tan sólo una imagen invertida que se refleja en los síntomas considerados en abstracto" Ibíd., p. 221. Esta ignorancia lleva postular la oposición como el principio genético.

$24 \quad$ Ibíd, p. 241

25 Ibíd., pp. $140-141$ 
inmediato que no se trata de reemplazarlo por la verdad, sino de destruirlo por completo para dar con otro ideal, en otro emplazamiento.

\section{La ciencia activa en la afinidad afirmativa entre pensamiento y vida}

Según Deleuze, Nietzsche localizó una primera matriz de este dogmatismo en el socratismo. Desde la perspectiva deleuziana, Nietzsche rechazó la disposición que Sócrates planteó en la cual la vida se encontraba al servicio del conocimiento y el pensamiento al servicio de la vida. Deleuze señala que aquí el conocimiento "es el mismo pensamiento pero sometido a la razón" ${ }^{26}$, y el instinto de conocimiento es el pensamiento dominado por la reacción. Esto es así ya que lo que gobierna cada ámbito es la limitación, porque "son los mismos límites que el conocimiento racional fija a la vida, pero también que la vida razonable fija al pensamiento", y agrega luego que en tal marco "la vida está sometida al conocimiento al mismo tiempo que el pensamiento está sometido a la vida". ${ }^{27}$ Como respuesta a este esquema, Nietzsche proyectó una crítica del conocimiento mediante la cual hacer ingresar pensamiento y vida en un mecanismo de progresiva afirmación a partir de una estimulación recíproca:

Un pensamiento que fuese hasta el final de lo que puede la vida, un pensamiento que llevase a la vida hasta el final de lo que puede. En lugar de un conocimiento que opone a la vida, establecer un pensamiento que afirmaría la vida. La vida sería la fuerza activa del pensamiento, pero el pensamiento el poder afirmativo de la vida. ${ }^{28}$

En este devenir, el pensamiento se haría activo, dejando de ser una razón, y la vida se volvería afirmativa, dejando de ser reacción. Debido a que cada término dice sí a su respectiva alteridad, la fuga del nihilismo socrático sería factible como mutua liberación: aquello que potencia al pensamiento sería la ruptura con el gobierno que el

$26 \quad$ Ibíd., p. 142

27 Ibídem

28 Ibíd., pp. 142-143 
conocimiento ejerce hacia la vida, la emancipación de la vida respecto del pensamiento racional; y tal superación del pensamiento respecto de la vida conservadora y limitada permite el devenir afirmativo de esta última. El significado de pensar que emerge es entonces "inventar nuevas condiciones de vidas". 29

Según Deleuze dicha afinidad entre pensamiento vida es la esencia del arte. A partir de una concepción del arte como más alto poder de lo falso (y de una interpretación de la apariencia no como negación de lo real sensible sino como selección de lo falso), la verdad adquiere la significación de realización del poder, elevación a la mayor potencia. ${ }^{30}$ Dicha alianza entre pensamiento y arte puede advertirse en la "doctrina" del perspectivismo nietzscheano: "No hay ilusiones del conocimiento, sino que el propio conocimiento es una ilusión: el conocimiento es un error, aun peor, una falsificación." ${ }^{31}$

Esta ataque a la configuración racionalista e idealista de la articulación entre pensamiento y vida no conduce a una completa cancelación de la noción de verdad, sino a una profunda reformulación de la misma. Esto es así ya que Deleuze propone, en base a lo anterior, lo que podría llamarse un auténtico programa epistemológico para el desarrollo de una concepción de ciencia a la altura de las intuiciones nietzscheanas. ${ }^{32}$ Para desbrozar el camino hacia la superación de la abstracción nihilista, lo que emerge como problema mayor es la necesidad de forjar una "nueva imagen del pensamiento". Habría tres implicancias para destacar al respecto, que pueden entenderse como las coordenadas de una ciencia post-nihilista:

1- Contra la idealización del pensamiento, se impone una topología y tipologia. Mientras que la imagen dogmática heredada por la tradición esencializa al pensamiento, atribuyéndole una "recta naturaleza" y una relación igualmente natural

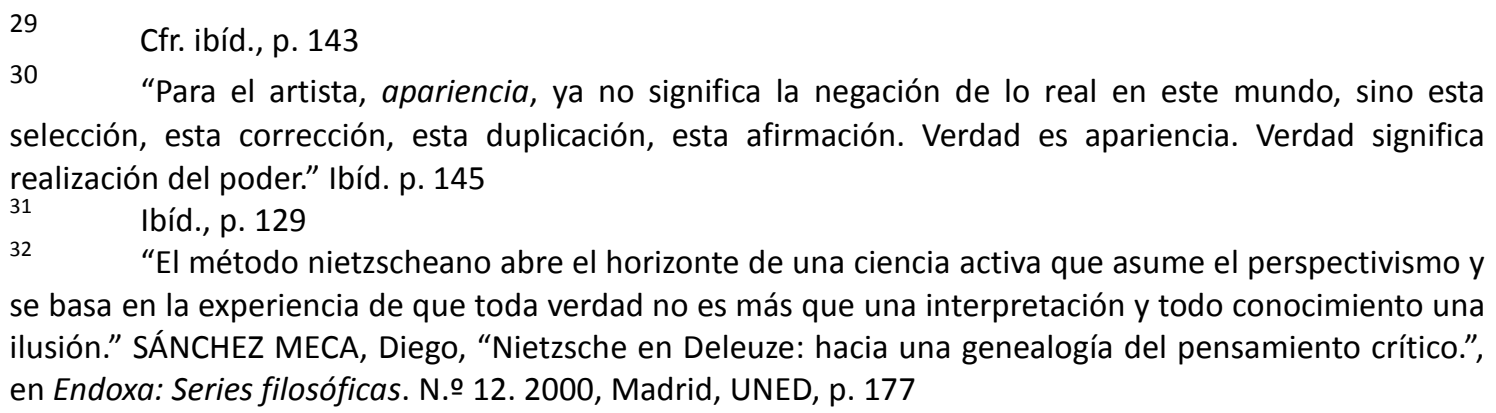
se basa en la experiencia de que toda verdad no es más que una interpretación y todo conocimiento una ilusión." SÁNCHEZ MECA, Diego, "Nietzsche en Deleuze: hacia una genealogía del pensamiento crítico.", en Endoxa: Series filosóficas. N.o 12. 2000, Madrid, UNED, p. 177 
con la verdad, esa indeterminación debe ser rechazada según la estimación de las condiciones reales de su producción: los matices y grados de las cualidades de las fuerzas que se apoderan del propio pensamiento. El sentido y el valor reemplazan la noción de verdad en sí, determinándola ahora en función de una tipología pluralista y una topología. ${ }^{33}$

2- El enemigo del pensamiento no es el error sino la estupidez. De modo correlativo al ideal de autosuficiencia mencionado antes, la imagen dogmática supone que si para pensar basta ejercer sus facultades naturales lo problemático reside en todo elemento exterior que perturbe ese ejercicio; es decir, el error. Por el contrario, según Deleuze, lo que amenaza los logros del pensamiento es la "estupidez", entendida como una estructura del pensamiento. Lo estúpido se corresponde a las limitaciones específicas de cada época que separan al pensar de lo que puede de un modo interno (y no como accidentes que comprometerían a una facultad en sí misma óptima), sinsentidos que en su desarrollo son indiferentes tanto al error como a lo verdadero. ${ }^{34}$ El papel del pensamiento debe consistir entonces en una crítica de la estupidez y la bajeza contemporáneas.

3- La conducción del pensamiento no requiere de un método sino de la activación de su potencia. La naturalización dogmática del pensamiento postula que es necesario un método para despejar los errores, de modo tal que una cierta construcción (normativa) reconduciría a lo esencial del saber. Así, mientras que la promesa del método como garantía de validez consagra la abstracción ya que no deja de presuponer la recta naturaleza del pensar, según Deleuze lo que Nietzsche recuperó como "herramienta" para una verdad afirmativa fue la selección: es necesario que pensamiento sea objeto de una violencia para que alcance un devenir activo. Esta

33 "Se trata de saber a qué región pertenecen ciertos errores y ciertas verdades, cuál es su tipo, quien las formula y las concibe." DELEUZE, Gilles, Nietzsche y la filosofía. Op cit., p. 149

34 "La estupidez no es un error ni una sarta de errores. Se conocen pensamientos imbéciles, discursos imbéciles construidos totalmente a base de verdades; pero estas verdades son bajas, son las de un alma baja, pesada y de plomo. La estupidez y, más profundamente, aquello de lo que es síntoma: una manera baja de pensar. He aquí lo que expresa por derecho el estado de un espíritu dominado por fuerzas reactivas." Ibíd, pp. 148-149 
coacción consiste en la asunción de la cultura como adiestramiento y selección del pensar. $^{35}$

En función de lo anterior, es factible comprender una nota particular dentro de la lectura deleuziana del corpus nietzscheano: la suposición según la cual la crítica de Nietzsche a la ciencia no pretendió denunciar un exceso sino exponer una falta, el fracaso a la hora de determinar efectivamente lo real. En efecto, Deleuze señala que para Nietzsche el problema del pensamiento moderno, incluyendo a la ciencia, es su tendencia a abstraerse de la diferencia real, reduciendo la elemental disparidad de todo lo existente: “Con razón o sin ella, Nietzsche cree que la ciencia, cuando afronta la cantidad, tiende siempre a igualar las cantidades, a compensar las desigualdades. ${ }^{\prime 36} \mathrm{Si}$, por lo tanto, el problema de la ciencia moderna cabe plantearse en términos de un déficit, esta abstracción puede transformarse recuperando los derechos de eso que fue excluido. Por lo cual Deleuze señala, siguiendo a Nietzsche, que tanto las ciencias naturales como las ciencias del hombre pueden cumplir dicha tarea si se conserva una suerte de fidelidad a la realidad concreta, asumida como fluctuación de la acción. Así, la investigación de fenómenos no puede pensarse sin concebir su acción misma, su lectura de aquello que pasa, al margen de la diferencia y el dinamismo. ${ }^{37}$ La clave de esta recuperación de la ciencia reside en la necesidad de advertir la jerarquía que la actividad guarda dentro del fenómeno de la acción por sobre la reactividad. ${ }^{38}$

Si dentro de la ontología nietzscheana que Deleuze reconstruye lo activo vale más que lo pasivo, el motivo reside en que es la actividad en su grado más alto lo que expresa la diferencia y la hace repetir. Se trata del nivel superior al cual puede llegar la actividad cuando deviene no solo actividad sino transformación. Aceptando esto, dentro de un análisis dado mantenerse en el nivel de la pasividad, de la reacción o la adaptación implica no comprender el fenómeno en su realidad, permanecer en la

\footnotetext{
$35 \quad$ Cfr. Ibíd., pp. 152-153

$36 \quad$ Ibíd., p. 67

37 "No se debe concebir la medida de las fuerzas como un procedimiento de física abstracta, sino corno el acto fundamental de una física concreta, no como una técnica indiferente, sino como el arte de interpretar la diferencia y la cualidad independientemente del estado de hecho..."Ibíd., p. 85

38 "Reactivo es una cualidad original de la fuerza, pero que sólo puede ser interpretada como tal en relación con lo activo, a partir de lo activo." Ibíd., p. 64.
} 
superficie de la acción. ${ }^{39}$ En consecuencia, para Deleuze la crítica nietzscheana dirigida a las tendencias de pensamiento contemporáneo que pretendían superar la clásica abstracción metafísica puede sintetizarse en el fatalismo ante la realidad, actitud que surge del desconocimiento de la jerarquía inseparable de la diferencia. ${ }^{40}$

Debido a que las tres "coordenadas" que trazan las condiciones de una nueva imagen del pensamiento apelan a la importancia fundamental de la actividad, al reconocimiento de la productividad (y no de la representación o especularidad) como única naturaleza del pensar, es factible suponer que la realización de una ciencia en tal orientación se identificaría con la selección de la vida que según Deleuze se efectuaría a partir de la destrucción del nihilismo: "De la afirmación [gobernando sobre la negación] derivan los nuevos valores: valores desconocidos hasta este momento, es decir hasta el momento en que el legislador ocupa el lugar del «sabio», la creación, la del propio conocimiento, la afirmación, la de todas las negaciones conocidas." ${ }^{41}$

\section{A propósito de la disolución del conocimiento y la emergencia de una ciencia} activa

\footnotetext{
$39 \quad$ “...lo que de todas maneras parece pertenecer a la ciencia, y también a la filosofía, es el afán de sustituir las relaciones reales de fuerza por una relación abstracta, supuesta capaz de expresarlas todas, como una «medida». (...) se acaba siempre por sustituir las actividades reales (crear, hablar, amar, etc.) por el punto de vista de un tercero sobre estas actividades: se confunde la esencia de la actividad con el beneficio de un tercero" ibíd., p. 106

$40 \quad$ "Esto es lo que caracteriza principalmente el positivismo y el humanismo del librepensador: el 'fatalismo', la incapacidad de interpretar, la ignorancia de las cualidades de la fuerza. (...) La crítica del librepensamiento es un tema fundamental en la obra de Nietzsche. Sin duda porque esta crítica descubre un punto de vista según el cual diversas ideologías pueden ser atacadas a la vez: el positivismo, el humanismo, la dialéctica." Ibíd., p. 87-88. Parafraseando a Marx, podría decirse que según Deleuze, sólo puede haber ciencia de lo activo: "Cuando la ciencia deja de utilizar conceptos pasivos, deja de ser un positivismo, pero la filosofía deja de ser una utopía, un ensueño sobre la actividad que compensa dicho positivismo." Ibíd., p. 108

$41 \quad$ Ibíd. p. 243. A partir de estos lineamientos Deleuze re-planteará la idea de pensamiento crítico en términos de una semiótica activa de los complejos afectivos. Concretamente, se trata de suponer que si al pensamiento le cabe la posibilidad de intervenir en el curso de la reproducción de las formas de vida y rectificar las derivas patológicas, es en la medida en que se interprete un fenómeno (un signo) dado según la ascendencia del complejo afectivo, es decir de la corporalidad inseparable de esa señal o signo. La crítica se practica así en estrecha conexión con una clínica, en tanto la configuración de la afectividad, la modalidad de funcionamiento de las pulsiones o realidad deseante constituye un criterio decisivo en la evaluación de las formas de vida Ver DELEUZE, Gilles, Félix, GUATTARI, El Antiedipo. Capitalismo y esquizofrenia. Trad. Francisco Monge. Paidós, Buenos Aires, 2009, p. 115 y p. 18, y Deleuze, Gilles. Crítica y clínica. Trad. Thomas Kauf. Anagrama, Barcelona, 1996, pp. 9 y ss.
} 
En función de lo expuesto, resulta claro que las primeras implicancias que caben extraerse del tratamiento conferido por Deleuze al tema del conocimiento en el marco de su lectura de Nietzsche necesitan atender a su condición problemática y negativa. Si el conocimiento es interpretado como error, ficción o falsedad es asimismo valorado como expresión de una voluntad baja, a cuya reproducción contribuye limitando al pensamiento al formalismo de la razón y manteniendo a la vida en un nivel adaptativo. Si bien el conocimiento no constituye por su propia cuenta todo este "fenómeno", si bien no agota la totalidad del acontecimiento del nihilismo (ya que éste consiste en un modo de vida cuya característica es mantener afines el deseo de nada y la pasividad), sí actúa de manera decisiva en el desarrollo de esta voluntad al proveer un medio de estratégica relevancia: el refugio más seguro acorde con los tiempos. Lo que Nietzsche supo advertir en su Genealogía de la moral (y Deleuze recuperar) es el servicio que prestaba la ciencia de su época al ideal asćetico.

Sin embargo, los elementos expuestos permiten también evidenciar que ya en ocasión de este libro Deleuze ensayó la formula que más tarde precisaría en ¿Qué es la filosofía?: hacer de la filosofía un pensamiento constructivo aproximando el planteamiento de problemas y la recreación de conceptos. ${ }^{42}$ En este sentido, los clásicos problemas de la teoría del conocimiento tales como su misma posibilidad, el debate entorno de su origen en términos de razón o de experiencia, el diseño de reglas definitivas para su práctica o la eventual demarcación de sus límites pierden relevancia crítica ya que se muestran como síntomas de una cuestión más apremiante: la ubicación del pensamiento como elemento hostil a la vida. Podría decirse que esto se condensa en la crítica al concepto de verdad, específicamente a su capacidad para expresar una indiferenciación de lo real, personificando diversamente el núcleo del ascetismo, el "deseo de otro mundo". Sin embargo, si el nihilismo sobrevive gracias a la creencia en una verdad en sí, en virtud de la mixtificación del pensamiento como

42 "Criticar no significa más que constatar que un concepto se desvanece, pierde sus componentes o adquiere otros nuevos que lo transforman cuando se lo sumerge en un ambiente nuevo. Pero quienes critican sin crear, quienes se limitan a defender lo que se ha desvanecido sin saber devolverle las fuerzas para que resucite, constituyen la auténtica plaga de la filosofía." DELEUZE, Gilles, GUATTARI, Félix, ¿Qué es la filosofía? Trad. Thomas Kauf. Barcelona, Anagrama, 2009, p. 34 
facultad universal, natural y autosuficiente, estos elementos anticipan en cierto modo la dimensión positiva y constructiva de la crítica.

En función de esto último, es posible considerar que la operación crítica que Deleuze realiza es una selección del pensamiento, ya que la separación de las condiciones que lo vuelven una abstracción no supone su término final sino la instancia negativa de su reformulación, el paso preliminar para la elucidación de una nueva imagen del pensamiento. En este caso, si la religión puede tomarse como la expresión cultural que se muestra más afín al nihilismo, el arte se presenta como antídoto a esto, como el recurso clave del espíritu trágico que festeja la pluralidad y que hace posible la selección del pensamiento.

El contraste que se marca entre la verdad en sí propia del ideal asćetico y la ciencia activa afín a un pluralismo afirmativo indica una depuración sobre la capacidad cognoscitiva del pensamiento. La crítica al conocimiento podría leerse como un ataque a la proyección de una generalidad en el pensar, generalidad de cuya disolución la crítica sólo recupera específicas expresiones del pensar: el arte que eleva indefinidamente el poder de lo falso y la ciencia por cuya lucidez se descubren las fuerzas activas. El rasgo que sintetiza la problematicidad del conocimiento sería entonces su complicidad con la representación, es decir su contribución a la indiferenciación del ser, tendencia concomitante a la creencia en una identidad entre pensamiento y realidad. Por esto mismo se revela de fundamental importancia la cuestión de la creación en la concepción de una ciencia activa. A su vez, si la mayor implicación gnoseológica del pluralismo nietzscheano leído por Deleuze es la separación establecida entre el conocimiento y la ciencia activa, este movimiento se muestra profundamente deudor de los supuestos ontológicos que acompañan la reconstrucción del corpus nietzscheano.

A partir de la convergencia propuesta entre la voluntad de poder y la doctrina del eterno retorno la naturaleza no es entendida como un mecanismo regular sujeto a leyes invariables, sino como pluralidad asimétrica de pura variación, donde lo regular se subordina a lo imprevisible. Así, podría decirse que la faceta "artista" del ser supera a la mecánica o incluso "jurídica" (como estricta sujeción a leyes). El énfasis puesto por 
Deleuze en la naturaleza original de la jerarquía, es decir la tesis de la subordinación de toda identidad a la diferencia, tiene como efecto un doble movimiento: no se niega el idealismo metafísico sin dejar de cuestionar cualquier realismo ingenuo, sea materialista o empirista. Este cuestionamiento obliga a considerar que lo único existente es una complejidad tal que para desarrollar un pensamiento a su altura es necesario retomar la idea de "principios". La revisión del giro inmanente característico de la modernidad encuentra de este modo el desafío de indagar en la posible afinidad entre esas instancias que tradicionalmente fueron vistas como excluyentes: principios y devenir, lógica y existencia.

De este modo, es factible suponer que el interés en no confundir la crítica nietzscheana con un reemplazado de ideales al cual se aludía durante la exposición de la dramatización de la verdad apunta a enfatizar lo que podría llamarse el "formalismo" depurado de sedimentos metafísicos propio de la genealogía: si no cabe conformarse ante la facticidad de lo existente, considerando lo real, los hechos, abstraídos de principios concretos, tampoco postular que estos principios son externos, separados de sus efectos. En este punto puede advertirse la particularidad de la propuesta deleuziana tomada en su contexto histórico: una filosofía de la multiplicidad debería saber mantenerse a distancia tanto de la postulación de condiciones ya siempre presentes, arraigadas en un origen sin posibilidad de cambio (la subjetividad constituyente que Kant legara a la modernidad, y que la fenomenología supo cultivar), como también de la apuesta por considerar a la positividad de la existencia derivada de condiciones por completo impersonales y autónomas (las relaciones diacrónicas y sincrónicas que a partir de la lingüística de Saussure el movimiento estructuralista tomo como regla). El empirismo superior procura descartar los supuestos de sustancias psíquicas al margen de toda la potencia del cambio y asimetría, como también una sistematicidad formal autosuficiente. ${ }^{43}$

\footnotetext{
43 Según esta importancia concedida por parte de Deleuze a la cuestión de una recuperación de la reflexión ontológica pueden comprenderse las limitaciones de la lectura practicada por el también francés Pascal Engel. En un artículo dedicado a caracterizar el así llamado "post-estructuralismo", Pascal Engel focaliza su reconstrucción especialmente en el aporte de Deleuze a esa corriente filosófica. Mientras que un acierto de Engel consiste en advertir la importancia que conserva el componente nietzscheano en Deleuze, en tanto matriz conceptual de diversas líneas problemáticas, no logra percibir la presencia de una genuina indagación en lo relativo a las condiciones de la determinación que el
} 


\section{Bibliografía}

- Althusser, Louis, BALIBAR, Etienne, Para leer el Capital. Trad. Marta Harnecker. Siglo XXI, Buenos Aires, 2004

- DELEUZE, Gilles, "Conclusiones sobre la voluntad de poder y el eterno retorno", en La isla desierta y otros textos. Textos y entrevistas (1953-1974). Trad. José Luis Pardo, Valencia, Pre-textos, 2005

- ---------------. Diferencia y repetición. Trad. María Silvia Delpy y Hugo Beccacece. Buenos Aires, Amorrortu, 2002

- - ------------ Nietzsche y la filosofía. Trad Carmen Artal. Barcelona, Anagrama, 2008

- - ---------- Crítica y clínica. Trad. Thomas Kauf. Anagrama, Barcelona, 1996

- DELEUZE, Gilles, Félix, GuATTARI, F. El Antiedipo. Capitalismo y esquizofrenia. Trad. Francisco Monge. Paidós, Buenos Aires, 2009

-

Barcelona, Anagrama, 2009

- ENGEL, Pascal, "The decline and fall of the French Nietzscheo-Structuralism", en Smith, Barry (comp.) European philosophy and the american academy. Illinois, Monist Library of Philosophy, 1994,

- HABERMAS, Jurgen, Teoría de la acción comunicativa I. Racionalidad de la acción y racionalización social. Trad. Manuel Jiménez Redondo. Madrid, Taurus, 2003

pensamiento realiza de lo que acontece. De este modo, se vuelve "poco afortunado" el señalamiento de una presunta contradicción en Deleuze, la cual estaría mantenida entre la promoción del abandono de la idea de verdad $\mathrm{y}$, correlativamente, de cualquier proyecto epistemológico, y entre la adhesión a un relativismo gnoseológico que ocultaría mal su espíritu positivista: “"Lo que resulta sorprende [en Deleuze] es que la apología del caos, del indeterminismo, etc. está acompañada de una perspectiva positivista sobre las teorías científicas, según la cual tales teorías no tratan de elucidar la naturaleza de la realidad sino que son sólo instrumentos para producir 'efectos'." ENGEL, Pascal, "The decline and fall of the French Nietzscheo-Structuralism", en Smith, Barry (comp.) European philosophy and the american academy. Illinois, Monist Library of Philosophy, 1994, pp. 30-31. (Traducción propia). Esta "contradicción" sólo surge si se pasa por alto la existencia de un criterio evaluador en el pensamiento, y su afinidad con la dimensión genética de toda realidad positiva, desatención esta que deja a la variabilidad del ser como simple cambio, y hace de la relativa determinación del saber una absoluta indeterminación. 
- HeIdegger, Martin, El Ser y el tiempo. Trad José Gaos. México, Fondo de Cultura Económica, 197

- HUSSERL, Edmund, La crisis de las ciencias europeas y la fenomenología transcendental. Trad. Jacobo Muñoz y Salvador Más. Barcelona, Critica, 1991

- SÁNCHEZ MECA, Diego, "Nietzsche en Deleuze: hacia una genealogía del pensamiento crítico.", en Endoxa: Series filosóficas. N.ํ 12. 2000, Madrid, UNED 